\title{
Leishmaniasis Research in India: A Scientometric Assessment of Publications during 2008-17
}

\author{
K K Mueen Ahmed ${ }^{1}$, B. M. Gupta ${ }^{2 *}$, Ritu Gupta ${ }^{3}$
}

\section{K K Mueen Ahmed ${ }^{1}$}

\section{B. M. Gupta ${ }^{2 *}$}

Ritu Gupta ${ }^{3}$

'Phcog.Net and SciBiolMed.Org, Bengaluru, Karnataka, INDIA.

21173 Sector 15, Panchkula 134113 , Haryana, INDIA.

${ }^{3} 1$ K/A Arjun Nagar, Safdarjang Enclave, New Delhi 110029, INDIA.

\section{Correspondence:}

\section{B. M. Gupta}

1173 Sector 15, Panchkula 134 113, Haryana, INDIA.

E-mail: bmgupta1@gmail.com

\section{History}

- Submission Date: 25-4-2018;

- Review completed: 6-07-2018;

- Accepted Date: 22-08-2018.

DOI : 10.5530/ijmedph.2018.3.21

Article Available online

http://www.jimedph.org/v8/i3

\section{Copyright}

(c) 2018 Phcog.Net. This is an open-access article distributed under the terms of the Creative Commons Attribution 4.0 International license.

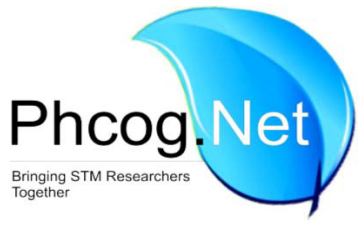

\begin{abstract}
The paper examines 1970 Indian publications on Leishmaniasis research, as covered in Scopus database during 2008-17, registering an annual average growth rate of $17.68 \%$, global publication share of $12.32 \%$, international collaborative publication share of $26.85 \%$ and qualitative citation impact averaged to 17.28 citations per paper. The top 10 most productive countries individually contributed global share from $4.13 \%$ to $22.95 \%$ with largest global publication share coming from Brazil (22.95\%), followed by USA (17.78\%), India (12.32\%), U.K., Iran and Spain (from $7.21 \%$ to $8.20 \%$ ), France. Germany, Italy and Switzerland (from 4.13\% to $5.95 \%$ ) during $2008-17$. Together, the 10 most productive countries accounted for $95.57 \%$ share of global publication output during 2008-17. Seven of the top 10 countries scored relative citation index above the world average of 1.32: Switzerland (2.17), Italy (2.0), U.K. (1.93), France (1.86), USA (1.80), Spain (1.58) and Germany (1.43) during 2008-17. Medicine, among subjects, accounted for the highest publications share $(55.43 \%)$, followed by biochemistry, genetics and molecular biology (32.94\%), immunology and microbiology (31.68\%), pharmacology, toxicology and pharmaceutics $(20.81 \%)$, chemistry $(7.77 \%)$ and agricultural and biological sciences (7.56\%) during 2008-17 The top 15 most productive Indian organizations and authors together contributed $78.38 \%$ and $57.06 \%$ respectively as their share of Indian publication output and $\mathbf{9 5 . 8 6 \%}$ and $52.23 \%$ respectively as their share of Indian citation output during 2008-17. Among the total journal output of 1603 papers, the top 15 journals contributed $26.17 \%$ share to the Indian journal output during 2008-17. 20 papers registered from 102 to 5725 citations per paper, which together received 211897 citations, leading to an average of 594.85 citations per paper during 2008-17.
\end{abstract}

Key words: Leishmaniasis research, Indian publications, Scientometrics, Bibliometrics.

\section{INTRODUCTION}

Leishmaniasis is a group of diseases and is caused by protozoan parasites from over 20 genus Leishmania species and is transmitted to humans by the bite of infected tiny (2 to $3 \mathrm{~mm}$ long) female insect vector phlebotomine sandfly, which breed in forest areas, caves, or the burrows of small rodents. Of the 500 known phlebotomine species, only 30 have been found to transmit leishmaniasis. The epidemiology of leishmaniasis depends on the characteristics of the parasite species, the local ecological characteristics of the transmission sites, current and past exposure of the human population to the parasite, and human behavior. Some 70 animal species, including humans, have been found as natural reservoir hosts of Leishmania parasites. ${ }^{1,2}$

Human infection can be caused by several species of Leishmania, which are included in four complexes: tropica (L. tropica, L. major, L. minor, and $L$. aethiopica), mexicana (L. mexicana, L. amazonensis, L. pifanoi, and L. venezuelensis), braziliensis or viannia (L. braziliensis, L. guyanensis, L. panamensis, and
L. peruviana), and donovani (L. donovani, L. infantum, L. chagasi, L. sinesis, and L. nilotica).

Only a small fraction of those infected by Leishmania parasites will eventually develop the disease. The disease affects some of the poorest people on earth and is associated with malnutrition, population displacement, poor housing, a weak immune system and lack of financial resources. Leishmaniasis is linked to environmental changes such as deforestation, building of dams, irrigation schemes and urbanization. Leishmaniasis threatens about 350 million men, women and children in 88 countries around the world. As many as 12 million people are believed to be currently infected, with about 1 to 2 million estimated new cases occurring every year. ${ }^{1-1}$

The disease can have a wide range of clinical symptoms, which may be cutaneous, mucocutaneous or visceral. Cutaneous leishmaniasis is the most common form. Visceral leishmaniasis (VL), also known as kala-azar is the most severe form, in which vital organs of the body are affected. It is fatal if left 
untreated in over $95 \%$ of cases. It is characterized by prolonged high fever, substantial weight loss, swelling of the spleen and liver, and anemia. Most cases occur in Brazil, East Africa and in South-East Asia. An estimated 50, 000 to 90, 000 new cases of VL occur worldwide each year. In 2015 , more than $90 \%$ of new cases reported to WHO occurred in 7 countries: Brazil, Ethiopia, India, Kenya, Somalia, South Sudan and Sudan. Of the estimated 500,000 people in the world infected each year, nearly 100,000 are estimated to occur in South East Asia Region. Three most affected countries in South East Asia Region are Bangladesh, India and Nepal. The disease is now being reported in 45 districts in Bangladesh, 52 in India and 12 in Nepal. ${ }^{1-2}$ Of the 54 endemic districts across the four states in India, Bihar state alone reports more than $70 \%$ of the total reported cases with approximately 35 million people at risk of contracting the disease. According to the National Vector Borne Disease Control Programme (NVBDCP, Central nodal agency of India) in 2016, $\mathrm{VL}$ cases have declined by $32 \%$ and $10 \%$ respectively in comparison with the year 2014. ${ }^{1-3}$

Cutaneous leishmaniasis (CL) is the most common form of leishmaniasis and causes skin lesions, mainly ulcers, on exposed parts of the body, leaving life-long scars and serious disability. It is estimated that between 600000 to 1 million new cases occur worldwide annually. About 95\% of CL cases occur in the Americas, the Mediterranean basin, the Middle East and Central Asia. In 2015 over two thirds of new CL cases occurred in 6 countries: Afghanistan, Algeria, Brazil, Colombia, Iran (Islamic Republic of) and the Syrian Arab Republic. It is estimated that between 600,000 to 1 million new cases occur worldwide annually. Mucocutaneous leishmaniasis leads to partial or total destruction of mucous membranes of the nose, mouth and throat. Over $90 \%$ of mucocutaneous leishmaniasis cases occur in Bolivia (the Plurinational State of), Brazil, Ethiopia and Peru. ${ }^{1-2}$

\section{Literature Review}

Only a few international and regional bliometric studies have been published in this field. Among the various international studies, GonzálezAlcaide, Huamaní, Jinseo and Ramos ${ }^{4}$ ] presented a bibliometric review of leishmaniasis research output (20,780 papers in 1846 journals) indexed in PubMed during a 66-year period. USA was the predominant country with $16.8 \%$ share, followed by Brazil (14.9\%) and India (9.0\%). The production ranking changed when the number of publications was normalized by population (Israel and Switzerland), by gross domestic product (Nepal and Tunisia), and by gross national income per capita (India and Ethiopia). For geographical area distribution, Europe took the lead with $31.7 \%$ share, followed by Latin America (24.5\%), etc. Gonzalez-Alcaide, Huamani, Park and Ramos ${ }^{5}$ studied leishmaniasis publications in the Medline database from 1945 to 2010, analyzing them according to bibliometric indicators and statistics from social network analysis. Examining aspects such as scientific production, diachronic evolution, and collaboration and configuration of the research groups in the field, the authors have considered the different types of Leishmania studied and the institutional affiliation and nationality of the authors. Soosaraeia, Akbar Khassehb, Fakharci and Hezarjaribic ${ }^{6}$ examined global publications on leishmaniasis during 2006-15. Brazil, USA, and India lead scientific production on leishmaniasis research. The United States, United Kingdom and Australia had the most collaborative share in performing the studies of leishmaniasis with each other. The study also identified leading organizations and authors. Among regional studies, PerillaGonzalez, Gomez-Suta, Delgado-Osorio, Hurtado-Hurtado, BaqueroRodriguez, Lopez-Isaza, Lagos-Grisales, Villegas, Soraya and RodriguezMorales $^{7}$ presented a bibliometric assessment of the Latin American scientific production (2857 articles) in leishmaniasis till 2013. Different study types, characterized by years, city/country of origin, journals and more productive authors, by country, cite and $\mathrm{H}$ index were examined. Since there was no comprehensive bibliometric study on Indian output, as a result we decided to undertake the present study.

\section{OBJECTIVES}

The main objectives of the present study are to study the performance of Indian Leishmaniasis research during 2008-17, deriving publications data from indexed publications in Scopus international database. The study had the following objectives: (i) To study the global research output and output of top 10 most productive countries including its output, global share, citation impact and share of international collaborative publications; (ii) To study the growth of Indian Leishmaniasis research output, its global share and its citation impact; (iii) To study the India's share of international collaboration publications and significant contribution of foreign partner countries; (iv) To study the Indian research output by broad subject areas and the dynamics of its growth and decline; (vi) To study the distribution of Indian research output by type of Leishmaniasis research; (v) To study the publication productivity and citation impact of top 15 Indian most productive organizations and authors; (vi) To study the modes of communication by Indian scholars and (vii) To study the bibliographic characteristics of high cited papers.

\section{METHODOLOGY}

The Leishmaniasis research publications landscape from 2008 through 2017 was identified and studied using the Scopus database (http://www. scopus.com). An keyword search was used to identify publications that contained the terms "Leishmania" or "Leishmaniasis" or "Cutaneous Leishmaniasis" or "Mucocutaneous Leishmaniasis" or "Visceral Leishmaniasis" in the "Article title tag" or "keyword tags" and restricting it to the period 2008-17 in "date range tag" was used for searching the global publication data (resulted into 15995 global publications) and this become the main search string. The main search string was later restricted to individual country name in "country tag" of 10 most productive countries (including India) one by one for obtaining publication data on individual top 10 most productive countries. The Indian search string had resulted into 1970 Indian publications on Leishmaniasis research during 2008-17. The Indian search string is further refined using provisions in Scopus database by "subject area tag", "country tag", "source title tag", "journal title name" and "affiliation tag", to get information on distribution of publications by subject, collaborating countries, author-wise, organization-wise and journal-wise. Separate search strategies were also developed to get information on different type of Leishmaniasis research. For citation data, citations to publications were also collected from date of publication till 16 April 2018.

(KEY("Leishmania" or "Leishmaniasis" or "Cutaneous Leishmaniasis" or "Mucocutaneous Leishmaniasis" or "Visceral Leishmaniasis") or TITLE ("Leishmania" or "Leishmaniasis" or "Cutaneous Leishmaniasis" or "Mucocutaneous Leishmaniasis" or "Visceral Leishmaniasis")) AND PUBYEAR > 2007 AND PUBYEAR < 2018

\section{ANALYSIS}

The global and Indian research output in Leishmaniasis research cumulated to 15995 and 1970 publications in 10 years during 2008-17, using a Scopus database. The annual output of world and India in Leishmaniasis research increased from 1355 to 1780 and from 145 to 211 publications from the year 2008 to the year 2017, registering $3.20 \%$ and $4.91 \%$ growth per annum. The cumulative global and Indian output in in Leishmaniasis research computing in 5 years increased from 7664 and 905 during 200812 to 8331 and 1065 during 2013-17, registering growth rate of $8.70 \%$ and $17.68 \%$, respectively. India's global publication share in Leishmani- 
asis research was $12.32 \%$ during $2008-17$, which increased from $11.81 \%$ to $12.78 \%$ from $2008-12$ to $2013-17$. Of the total Indian publications output, $81.37 \%$ (1603) was published as articles, $11.07 \%$ (218) as reviews, $2.94 \%(58)$ as letters, $1.07 \%(21)$ as editorials, $0.96 \%$ (19) as notes, $0.81 \%$ (16) each as short surveys and conference papers, $0.71 \%$ (14) as book chapters and 0.25 (5) as erratum. The citation impact of Indian publications on Leishmaniasis research averaged to 17.28 citations per publication (CPP) during 2008-17; five-yearly impact averaged to 27.07 CPP for the period 2008-12 which declined to $8.96 \mathrm{CPP}$ in the succeeding five-year 2013-17 (Table 1).

\section{International Collaboration}

India's share of internationally collaborative papers (ICP) in Leishmaniasis research was $26.85 \%$ during 2008 - 17 , which increased from $26.54 \%$ to $27.18 \%$ from $2008-12$ to $2013-17$. Among the leading countries contributing to internationally collaborative papers of India, USA topped the list with $38.75 \%$ share, followed by U.K. (19.85\%), Belgium (19.47\%),
Switzerland (18.15\%), Nepal (12.67\%), Australia and Bangladesh (7.56\% each), Canada and Spain (6.05\% each) during 2008-17. India's international collaborative publications share increased by $5.23 \%$ each in Canada and Spain, $4.70 \%$ in Germany and $0.46 \%$ in Australia, as against decrease by $10.77 \%$ in U.K., $8.24 \%$ in Nepal, $7.11 \%$ in Switzerland, $6.59 \%$ in USA, 3.88\% in Belgium and 1.82\% in Bangladesh from 2008-12 to 2013-17 (Table 2).

\section{Top 10 Most Productive Countries in Global Leishmaniasis Research}

The global research output in Leishmaniasis research had originated from as many as 158 countries in the world during 2008-17, of which 65 countries contributed 1-10 papers each, 57 countries 11-100 papers each, 25 countries 101-500 papers each, 5 countries 501-1000 papers, 4 countries 1001-2000 papers each and 2 countries 2001-3671 papers each. Top 10 most productive countries in Leishmaniasis research had contributed 661 to 3671 publications each during 2008-1917 (Table 3). Top 10 most

Table 1: Global and India ResearchOutput in Leishmaniasis Researchduring 2008-17

\begin{tabular}{|c|c|c|c|c|c|c|c|c|c|}
\hline \multirow[t]{2}{*}{ Period } & \multicolumn{6}{|c|}{ World } & \multicolumn{3}{|c|}{ India } \\
\hline & TP & $\mathrm{TC}$ & CPP & TP & $\mathrm{TC}$ & CPP & \%TP & ICP & \%ICP \\
\hline 2008 & 1355 & 35302 & 26.05 & 145 & 3087 & 21.29 & 10.70 & 34 & 23.45 \\
\hline 2009 & 1481 & 39402 & 26.60 & 150 & 3187 & 21.25 & 10.13 & 24 & 16.00 \\
\hline 2010 & 1517 & 33865 & 22.32 & 175 & 5130 & 29.31 & 11.54 & 55 & 31.43 \\
\hline 2011 & 1594 & 32929 & 20.66 & 219 & 4593 & 20.97 & 13.74 & 75 & 34.25 \\
\hline 2012 & 1717 & 33359 & 19.43 & 216 & 8501 & 39.36 & 12.58 & 58 & 26.85 \\
\hline 2013 & 1718 & 21095 & 12.28 & 206 & 2525 & 12.26 & 11.99 & 55 & 26.70 \\
\hline 2014 & 1857 & 16813 & 9.05 & 239 & 2331 & 9.75 & 12.87 & 75 & 31.38 \\
\hline 2015 & 1718 & 12699 & 7.39 & 215 & 3658 & 17.01 & 12.51 & 51 & 23.72 \\
\hline 2016 & 1758 & 6322 & 3.60 & 194 & 759 & 3.91 & 11.04 & 46 & 23.71 \\
\hline 2017 & 1780 & 1940 & 1.09 & 211 & 265 & 1.26 & 11.85 & 56 & 26.54 \\
\hline 2008-12 & 7664 & 174857 & 22.82 & 905 & 24498 & 27.07 & 11.81 & 246 & 27.18 \\
\hline 2013-17 & 8331 & 58869 & 7.07 & 1065 & 9538 & 8.96 & 12.78 & 283 & 26.57 \\
\hline 2008-17 & 15995 & 233726 & 14.61 & 1970 & 34036 & 17.28 & 12.32 & 529 & 26.85 \\
\hline
\end{tabular}

TP=Total Papers; TC=Total Citations; CPP=Citations Per Paper; ICP=International Collaborative Papers

Table 2: Publication Share of Leading Foreign Countries in India's Collaborative Papers (ICP) ResearchOutput in Leishmaniasis Research during 2008-17.

\begin{tabular}{|c|c|c|c|c|c|c|c|}
\hline \multirow[t]{2}{*}{ S.No } & \multirow{2}{*}{$\begin{array}{c}\text { Collaborative } \\
\text { Country }\end{array}$} & \multicolumn{3}{|c|}{ Number of ICP } & \multicolumn{3}{|c|}{ Share of ICP } \\
\hline & & 2008-12 & 2013-17 & $2008-17$ & 2008-12 & 2013-17 & 2008-17 \\
\hline 1 & USA & 104 & 101 & 205 & 42.28 & 35.69 & 38.75 \\
\hline 2 & U.K. & 63 & 42 & 105 & 25.61 & 14.84 & 19.85 \\
\hline 3 & Belgium & 53 & 50 & 103 & 21.54 & 17.67 & 19.47 \\
\hline 4 & Switzerland & 54 & 42 & 96 & 21.95 & 14.84 & 18.15 \\
\hline 5 & Nepal & 42 & 25 & 67 & 17.07 & 8.83 & 12.67 \\
\hline 6 & Germany & 18 & 34 & 52 & 7.32 & 12.01 & 9.83 \\
\hline 7 & Australia & 18 & 22 & 40 & 7.32 & 7.77 & 7.56 \\
\hline 8 & Bangladesh & 21 & 19 & 40 & 8.54 & 6.71 & 7.56 \\
\hline 9 & Canada & 8 & 24 & 32 & 3.25 & 8.48 & 6.05 \\
\hline \multirow[t]{2}{*}{10} & Spain & 8 & 24 & 32 & 3.25 & 8.48 & 6.05 \\
\hline & Indian Total & 246 & 283 & 529 & & & \\
\hline
\end{tabular}


Ahmed, et al.: Leishmaniasis Research in India:A scientometric Assessment

Table 3: Publication Output and Share (\%) of Top 10 MostProductive Countries in India'sLeishmaniasis Research during 2008-17.

\begin{tabular}{|c|c|c|c|c|c|c|c|c|c|c|c|c|c|c|}
\hline \multirow[t]{2}{*}{ S.No } & \multirow{2}{*}{$\begin{array}{l}\text { Name of the } \\
\text { Country }\end{array}$} & \multicolumn{3}{|c|}{ Number of Papers } & \multicolumn{3}{|c|}{ Share of Papers } & TC & CPP & ICP & \%ICP & HCP & $\% \mathrm{HCP}$ & $\mathrm{RCl}$ \\
\hline & & 2008-12 & 2013-17 & 2008-17 & 2008-12 & 2013-17 & 2008-17 & \multicolumn{7}{|c|}{ 2008-17 } \\
\hline 1 & Brazil & 1546 & 2125 & 3671 & 20.17 & 25.51 & 22.95 & 41855 & 11.40 & 942 & 25.66 & 18 & 0.49 & 0.78 \\
\hline 2 & USA & 1425 & 1419 & 2844 & 18.59 & 17.03 & 17.78 & 74707 & 26.27 & 1602 & 56.33 & 93 & 3.27 & 1.80 \\
\hline 3 & India & 905 & 1065 & 1970 & 11.81 & 12.78 & 12.32 & 34036 & 17.28 & 529 & 26.85 & 20 & 1.02 & 1.18 \\
\hline 4 & U.K. & 687 & 624 & 1311 & 8.96 & 7.49 & 8.20 & 36958 & 28.19 & 830 & 63.31 & 45 & 3.43 & 1.93 \\
\hline 5 & Iran & 465 & 742 & 1207 & 6.07 & 8.91 & 7.55 & 11827 & 9.80 & 145 & 12.01 & 2 & 0.17 & 0.67 \\
\hline 6 & Spain & 500 & 653 & 1153 & 6.52 & 7.84 & 7.21 & 26556 & 23.03 & 565 & 49.00 & 20 & 1.73 & 1.58 \\
\hline 7 & France & 475 & 476 & 951 & 6.20 & 5.71 & 5.95 & 25908 & 27.24 & 611 & 64.25 & 21 & 2.21 & 1.86 \\
\hline 8 & Germany & 415 & 427 & 842 & 5.41 & 5.13 & 5.26 & 17617 & 20.92 & 555 & 65.91 & 16 & 1.90 & 1.43 \\
\hline 9 & Italy & 322 & 355 & 677 & 4.20 & 4.26 & 4.23 & 19759 & 29.19 & 337 & 49.78 & 20 & 2.95 & 2.00 \\
\hline \multirow[t]{4}{*}{10} & Switzerland & 331 & 330 & 661 & 4.32 & 3.96 & 4.13 & 20980 & 31.74 & 574 & 86.84 & 20 & 3.03 & 2.17 \\
\hline & Total & 7071 & 8216 & 15287 & 92.26 & 98.62 & 95.57 & 310203 & 20.29 & 6690 & & 275 & 1.80 & 1.39 \\
\hline & WorldTotal & 7664 & 8331 & 15995 & & & & 233726 & 14.61 & & & & & \\
\hline & $\begin{array}{c}\text { Top } 10 \\
\text { Countries } \\
\text { share in World } \\
\text { Total }\end{array}$ & & & & & & & & & & & & & \\
\hline
\end{tabular}

TP=Total Papers; TC=Total Citations; $\mathrm{CPP}=$ Citations Per Paper; ICP=International Collaborative Papers; HCP=High Cited Papers

productive countries in Leishmaniasis research accounted for $95.57 \%$ global publication share during 2008-17, which increased from $92.26 \%$ to $98.62 \%$ from $2008-12$ to $2013-17$. Each of top 10 countries accounted for $4.13 \%$ to $22.95 \%$ global publication share during 2008-17, with Brazil accounting for the highest publication share (22.95\%), followed by USA (17.78\%), India (12.32\%), U.K., Iran and Spain (from 7.21\% to 8.20\%), France. Germany, Italy and Switzerland (from $4.13 \%$ to $5.95 \%$ ) during 2008-17. The global publication share in five years increased by $5.33 \%$ in Brazil, $2.84 \%$ in Iran, $1.31 \%$ in Spain, $0.98 \%$ in India and $0.06 \%$ in Italy, as against decrease by $1.56 \%$ in USA, $1.47 \%$ in U.K., $0.48 \%$ in Spain, $0.36 \%$ in Switzerland and 0.29\% in Germany from 2008-12 to 2013-17. Seven of the top 10 countries scored relative citation index above the world average of 1.32: Switzerland (2.17), Italy (2.0), U.K. (1.93), France (1.86), USA (1.80), Spain (1.58) and Germany (1.43) during 2008-17. Seven countries have achieved share of high cited papers above the average (1.65) of top 10 countries: U.K. (3.43), USA (3.27), Switzerland (3.03), Italy (2.95), France (2.21), Germany (1.90) and Spain (1.73) during 2008-17.

\section{Subject-Wise Distribution of Research Output}

The Indian Leishmaniasis research output published during 2008-17 is distributed over six sub-fields as identified in Scopus database classification, with medicine accounting for the highest publications share (55.43\%), followed by biochemistry, genetics and molecular biology (32.94\%), immunology and microbiology (31.68\%), pharmacology, toxicology and pharmaceutics (20.81\%), chemistry (7.77\%) and agricultural and biological sciences (7.56\%) during 2008-17. The activity index, which computes change in research activity in a discipline over time 2008-12 to 2013-17 (world average activity index of a given subject is taken as 100 ), witnessed increase in only chemistry (from 85.36 to 112.44 ), as against decline of research activity in medicine (from 101.46 to 98.76), biochemistry, genetics and molecular biology (from 100.62 to 99.47), immunology and microbiology (from 108.14 to 93.08), pharmacology, toxicology and pharmaceutics (from 102.47 to 97.90) and agricultural and biological sciences (from 111.03 to 90.63) from 2008-12 to 2013-17. Chemistry, among six subjects registered the highest citation impact per paper (23.06), followed by medicine (20.53), pharmacology, toxicology and pharmaceutics (16.68), biochemistry, genetics and molecular biology (14.63), immunology and microbiology (13.37) and agricultural and biological sciences(12.58) during 2008-17 (Table 4).

\section{Types of Leishmaniasis Research}

On classifying Indian Leishmaniasis research output by type of Leishmaniasis, it was observed that Visceral Leishmaniasis accounted for the largest publication share $(54.62 \%)$, followed by Cutaneous Leishmaniasis (3.20) and Mucocutaneous Leishmaniasis (0.25\%) during 2008-17. In terms of global publication share, again Visceral Leishmaniasis registered the highest share (21.86\%), followed by Mucocutaneous Leishmaniasis (4.76\%) and Cutaneous Leishmaniasis (2.90\%) during 2008-17. In terms of citation impact per paper, Visceral Leishmaniasis registered the highest impact of 16.38, followed by Cutaneous Leishmaniasis (7.52) and Mucocutaneous Leishmaniasis (4.205) during 2008-17.

\section{Profile of Top 15 Most Productive Indian Organizations}

Four Hundred Eighty Eight (488) organizations participated in Indian Leishmaniasis research, of which 340 organizations contributed 1-5 papers each, 81 organizations 6-10 papers each, 41 organizations 11-30 papers each, 14 organizations 31-50 papers each, 8 organizations 51-100 papers each and 4 organizations 101-201 papers each during 2008-17.

The productivity of 15 most productive organizations in Indian Leishmaniasis research varied from 39 to 301 publications and together they contributed 78.38\% (1544) publication share and 95.86\% (32628) citation share to its cumulative publications output during 2008-17. The scientometric profile of these 15 organizations is presented in Table 6 .

- Four of these organizations registered publications output greater than the group average of 102.93: Banaras Hindu University, Varanasi (301 papers), Indian Institute of Chemical Biology, Kolkata (258 papers), Central Drug Research Institute, Lucknow (212 papers) and Rajendra Memorial Institute of Medical Sciences, Patna (207 papers) during 2008-17; 
Table 4: Subject-Wise Breakup of IndianPublications in Leishmaniasis Researchduring 2008-17.

\begin{tabular}{|c|c|c|c|c|c|c|c|c|c|}
\hline \multirow[t]{2}{*}{ S.No } & \multirow[t]{2}{*}{ Subject* } & \multicolumn{3}{|c|}{ Number of Papers (TP) } & \multicolumn{2}{|c|}{ Activity Index } & \multirow{2}{*}{$\frac{\text { TC }}{2008-17}$} & \multirow{2}{*}{$\begin{array}{c}\text { CPP } \\
2008-17\end{array}$} & \multirow{2}{*}{$\begin{array}{c}\text { \%TP } \\
2008-17\end{array}$} \\
\hline & & 2008-12 & 2013-17 & 2008-12 & 2008-12 & 2013-17 & & & \\
\hline 1 & Medicine & 509 & 583 & 1092 & 101.46 & 98.76 & 22414 & 20.53 & 55.43 \\
\hline 3 & Immunology and Microbiology & 310 & 314 & 624 & 108.14 & 93.08 & 8340 & 13.37 & 31.68 \\
\hline 5 & Chemistry & 60 & 93 & 153 & 85.36 & 112.44 & 3528 & 23.06 & 7.77 \\
\hline \multirow[t]{2}{*}{6} & Agricultural and Biological Sciences & 76 & 73 & 149 & 111.03 & 90.63 & 1875 & 12.58 & 7.56 \\
\hline & India's Output & 905 & 1065 & 1970 & & & & & \\
\hline
\end{tabular}

- There is overlapping of literature covered under various subjects

TP=Total Papers; TC=Total Citations; $\mathrm{CPP}=$ Citations Per Paper

Table 5: Indian Publication Output by Type of Leishmaniasis Research, 2008-17.

\begin{tabular}{|c|c|c|c|c|c|c|c|}
\hline \multirow[t]{2}{*}{ S.No } & \multirow[t]{2}{*}{ Type of Anemia } & \multirow{2}{*}{$\begin{array}{c}\text { Global } \\
\text { GTP }\end{array}$} & \multicolumn{5}{|c|}{ India } \\
\hline & & & TP & TC & CPP & \%GTP & \%TP \\
\hline 1 & Cutaneous Leismaniasis & 2172 & 63 & 474 & 7.52 & 2.90 & 3.20 \\
\hline 2 & $\begin{array}{l}\text { Mucocutaneous } \\
\text { Leismaniasis }\end{array}$ & 105 & 5 & 21 & 4.20 & 4.76 & 0.25 \\
\hline \multirow[t]{2}{*}{3} & Visceral Leiamaniasis & 4923 & 1076 & 17626 & 16.38 & 21.86 & 54.62 \\
\hline & Total of India & 15995 & 1970 & & & & \\
\hline
\end{tabular}

GTP=Global Total Papers, TP=Total Papers; TC=Total Citations; CPP=Citations Per Paper; ICP=International Collaborative Papers

- Three organizations registered citation impact above the group average of 21.13 citations per publication: All India Institute of Medical Sciences, New Delhi (105.23), Postgraduate Institute of Medical Education and Research, Chandigarh (61.36) and Banaras Hindu University, Varanasi (22.25) during 2008-17;

- Five organizations contributed international collaborative publications share above the group average of 28.43\%: Banaras Hindu University, Varanasi (51.16\%),Institute of Pathology, New Delhi (50.85\%), National Institute of Pharmaceutical Education and Research, Mohali (33.33\%), Institute of Postgraduate Medical Education and Research, Kolkata (30.77\%) and Jawaharlal Nehru University, New Delhi (30.77\%) during 2008-17; and

- Three organizations registered the relative citation index above the group average (1.22) of all organizations: All India Institute of Medical Sciences, New Delhi (6.09), Postgraduate Institute of Medical Education and Research, Chandigarh (3.55) and Banaras Hindu University, Varanasi (1.29) during 2008-17.

\section{Profile of Top 15 Most Productive Authors}

Seven Hundred Forty Nine (749) authors participated in Indian Leishmaniasis research, of which 610 authors contributed 1-10 papers each, 86 authors 11-20 papers each, 45 authors 21-50 papers each, 6 authors 51-100 papers each and 2 authors 101-243 papers each during 2008-17.

The productivity of 15 most productive authors in Indian Leishmaniasis research varied from 37 to 243 publications. Together they contributed $57.06 \%$ (1124) Indian publication share and 52.23\% (17776) citation share during 2008-17. The scientometric profile of these 15 authors is presented in Table 7.
- Four authors registered publications output above the group average of 74.93: S. Sundar (243 papers), P. Das (205 papers), K. Pandey (86 papers) and A.Dube (82 papers) during 2008-17;

- Six authors registered impact above the group average of 15.81 citations per publication: J. Chakravarty (35.33), S. Sundar (23.37), N. Ali (20.0), S. Gupta (16.26), S. Roy (16.06), P. Salotra (15.94) during 2008-17;

- Seven authors contributed international collaborative publications share above the group average of $33.10 \%$ of all authors: S. Sundar (56.38\%), P. Salotra (54.55\%), S. Roy (47.06\%), V. Kumar (42.86\%), N. Ali (40.0\%), J. Chakravarty (35.9\%) and R. Madhubala (35.14\%) during 2008-17;

- Five authors registered the relative citation index above the group average (0.92) of all authors: J. Chakravarty (2.04), S. Sundar (1.35), N. Ali (1.16), S. Gupta (0.94) and S. Roy ().93) during 2008-17.

\section{Medium of Communication}

Seven Hundred Forty Nine (749) journals participated in Indian Leishmaniasis research, of which 440 journals contributed 1-5 papers each, 44 journals 6-10 papers each, 19 journals 11-20 papers each, 11 journals 21-50 papers each and 2 journals 51-84 papers each during 200817. Of the total Indian publications output in Leishmaniasis research, 98.53\% (1603) appeared in journals, $0.66 \%$ (13) in books, $0.56 \%(11)$ as book chapters, $0.15 \%$ (3) as conference proceedings and $0.25 \%(2)$ as trade publications during 2008-17. The top 15 most productive journals accounted for 19 to 84 papers each in India Leishmaniasis research and together accounted for $26.17 \%$ share (508 papers) of total journal publication output during 2008-17. The publication share of these top 15 most productive journals decreased from $26.43 \%$ to $25.95 \%$ between $2008-12$ and 2013-17. The top most productive journal (with 84 papers) was 
Table 6: Scientometric Profile of Top 15 Most Productive Organizationsin Leishmaniasis Research in India during 2008-17.

\begin{tabular}{|c|c|c|c|c|c|c|c|c|}
\hline S.No & Name of the Organization & TP & TC & CPP & HI & ICP & $\% \mathrm{ICP}$ & $\mathrm{RCl}$ \\
\hline 1 & Banaras Hindu University, Varanasi & 301 & 6696 & 22.25 & 42 & 154 & 51.16 & 1.29 \\
\hline 2 & Indian Institute of Chemical Biology, Kolkata & 258 & 3833 & 14.86 & 31 & 70 & 27.13 & 0.86 \\
\hline 3 & Central Drug Research Institute, Lucknow & 212 & 2806 & 13.24 & 27 & 24 & 11.32 & 0.77 \\
\hline 4 & Rajendra Memorial Institute of Medical Sciences, Patna & 207 & 2165 & 10.46 & 23 & 58 & 28.02 & 0.61 \\
\hline 5 & All India Institute of Medical Sciences, New Delhi & 82 & 8629 & 105.23 & 17 & 9 & 10.98 & 6.09 \\
\hline 6 & National Center for Cell Science, Pune & 64 & 615 & 9.61 & 13 & 12 & 18.75 & 0.56 \\
\hline 7 & Institute of Pathology, New Delhi & 59 & 920 & 15.59 & 17 & 30 & 50.85 & 0.90 \\
\hline 8 & Jadavpur University, Kolkata & 52 & 497 & 9.56 & 12 & 10 & 19.23 & 0.55 \\
\hline 9 & Jawaharlal Nehru University, New Delhi & 52 & 698 & 13.42 & 16 & 16 & 30.77 & 0.78 \\
\hline 10 & Postgraduate Institute of Medical Education and Research, Chandigarh & 47 & 2884 & 61.36 & 12 & 12 & 25.53 & 3.55 \\
\hline 11 & Indian Institute of Technology, Guwahati & 47 & 489 & 10.40 & 12 & 3 & 6.38 & 0.60 \\
\hline 12 & National Institute of Pharmaceutical Education and Research, Mohali & 42 & 495 & 11.79 & 12 & 14 & 33.33 & 0.68 \\
\hline 13 & Vardhman Mahavir Medical College and Safdarjung Hospital, New Delhi & 42 & 528 & 12.57 & 13 & 11 & 26.19 & 0.73 \\
\hline 14 & Bose Institute, Kolkata & 40 & 654 & 16.35 & 14 & 4 & 10.00 & 0.95 \\
\hline \multirow[t]{4}{*}{15} & Institute of Postgraduate Medical Education and Research, Kolkata & 39 & 719 & 18.44 & 17 & 12 & 30.77 & 1.07 \\
\hline & Total of 15 Indian organizations & 1544 & 32628 & 21.13 & 18.53 & 439 & 28.43 & 1.22 \\
\hline & Total of India & 1970 & 34036 & 17.28 & & & & \\
\hline & Share of top 15Indian organizations in India's total output & 78.38 & 95.86 & & & & & \\
\hline
\end{tabular}

TP=Total Papers; TC=Total Citations; CPP=Citations Per Paper; HI=h-index; ICP=International Collaborative Papers; RCI=Relative Citation Index

Table 7: Scientometric Profile of Top 15 Most Productive Authors in Leishmaniasis Research in India during 2008-17.

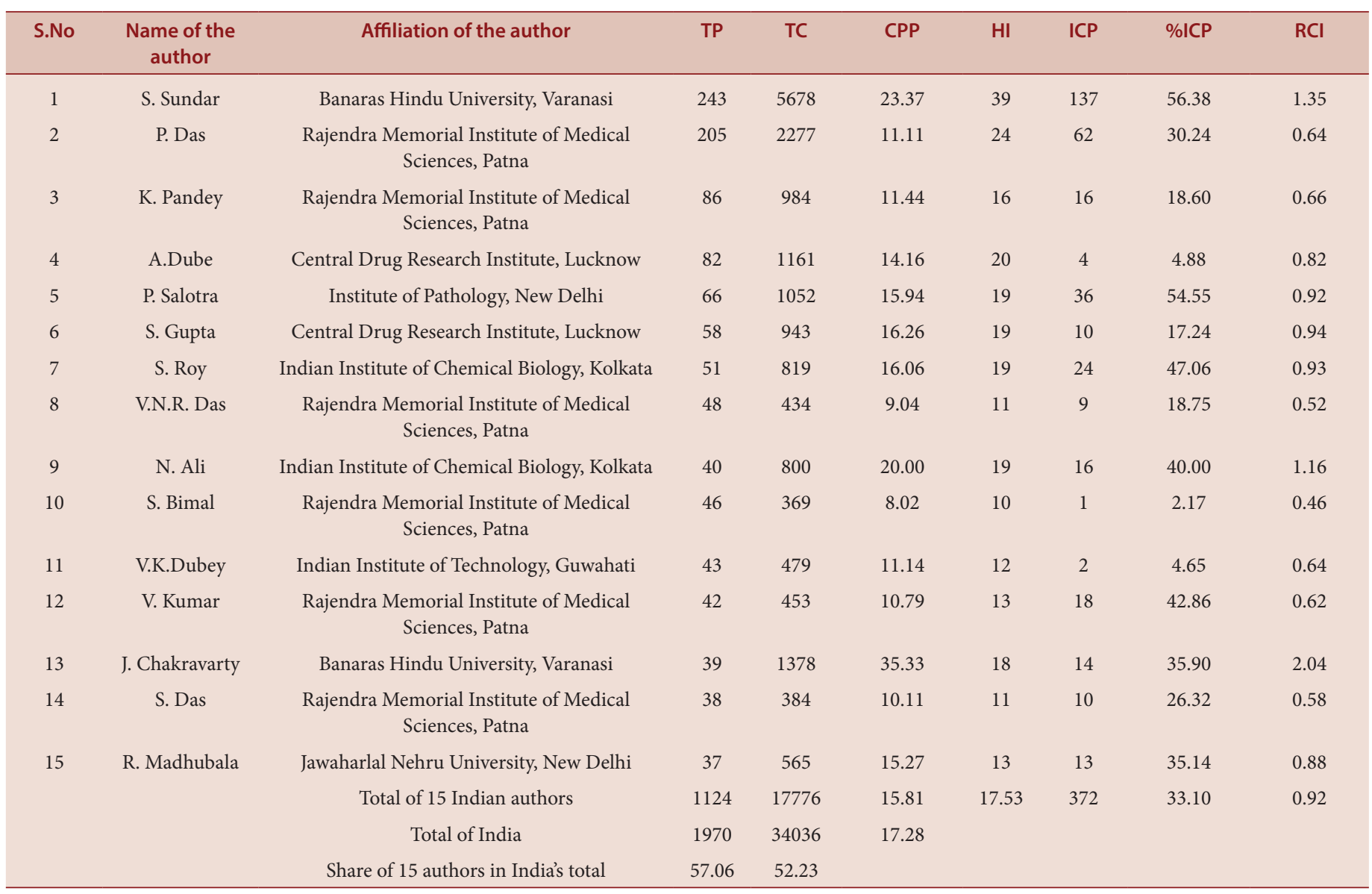

TP=Total Papers; TC=Total Citations; CPP=Citations Per Paper; HI=h-index; ICP=International Collaborative Papers; RCI=Relative Citation Index 
Table 8: Top 15 Most Productive Journals in Leishmaniasis Research in India during 2008-17.

\begin{tabular}{|c|c|c|c|c|}
\hline \multirow[t]{2}{*}{ S.No } & \multirow[t]{2}{*}{ Name of the Journal } & \multicolumn{3}{|c|}{ Number of Papers } \\
\hline & & 2008-12 & 2013-17 & 2008-17 \\
\hline 1 & PLOS Neglected Tropical Diseases & 25 & 59 & 84 \\
\hline 2 & PLOS One & 30 & 39 & 69 \\
\hline 3 & Experimental Parasitology & 20 & 22 & 42 \\
\hline 4 & American Journal of Tropical Medicine and Hygiene & 11 & 30 & 41 \\
\hline 5 & Antimicrobial Agents & 13 & 22 & 35 \\
\hline 6 & Parasitology Research & 18 & 13 & 31 \\
\hline 7 & Bioorganic and Medicinal Chemistry Letters & 11 & 15 & 26 \\
\hline 8 & Tropical Medicine and International Health & 19 & 7 & 26 \\
\hline 9 & Journal of Immunology & 12 & 12 & 24 \\
\hline 10 & Indian Journal of Medical Research & 14 & 9 & 23 \\
\hline 11 & Journal of Antimicrobial Chemotherapy & 19 & 4 & 23 \\
\hline 12 & Acta Tropica & 8 & 14 & 22 \\
\hline 13 & European Journal of Medicinal Chemistry & 11 & 11 & 22 \\
\hline 14 & Indian Journal of Dermatology, Venereology and Leprology & 9 & 12 & 21 \\
\hline \multirow[t]{4}{*}{15} & Transactions of the Royal Society of Tropical Medicine and Hygiene & 16 & 3 & 19 \\
\hline & Total of 15 journals & 236 & 272 & 508 \\
\hline & Total India journal output & 893 & 1048 & 1941 \\
\hline & Share of top 15 journals in Indian journal output & 26.43 & 25.95 & 26.17 \\
\hline
\end{tabular}

PLOS Neglected Tropical Diseases, followed by PLOS One (69 papers), Experimental Parasitology (42 papers), American Journal of Tropical Medicine and Hygiene (41 papers), Antimicrobial Agents (35 papers), etc. during 2008-17 (Table 6).

\section{High Cited Papers}

Out of 1970 papers in Indian Leismaniasis research, around 1 percent $(20,1.01 \%)$ received 102 to 5725 citations per paper in 10 years (200817). These 20 highly cited papers together cumulated 211897 citations, with an average of 594.85 citations per paper. Amongst 20 highly cited papers, 14 received 101-200 citations each, 2 received 201-399 citations each, 1 received 490 citations and the remaining 3 papers were in 1421-5725 citation range. These 20 highly cited papers originated from 65 countries. The USA, U.K. and Switzerland accounted for the highest number of papers (6), followed by Belgium (4 papers), Canada, Germany and Nepal (3 papers each), Australia and Bangladesh (2 papers each), etc. Top Indian organizations participating in 20 highly cited papers include Banaras Hindu University (11 papers), All India Institute of Medical Sciences, New Delhi (4 papers), Postgraduate Institute of Medical Education and Research, Chandigarh (2 papers), etc. The leading authors participating in 20 high cited papers were: S. Sundar (8 papers), J. Chakravarty (6 papers, etc. These 20 highly cited papers were published in 16 journals, with 4 papers in The Lancet, followed by 2 papers in Clinical Infectious Diseases and 1 paper each in Asia and Pacific Journal of Tropical Medicine, Colloid and Surfaces B, Expert Opinion in Investigative Drugs, Expert Opinion in Pharmacotherapy, Genome Research, International Journal of Environmental Research and Public Health, Journal of Antibiotics, Journal of Pharmaceutical Sciences, Journal of Vector Borne Diseases, Medicinal Research Review, New England Journal of Medicine, PLOS Neglected Diseases, PLOS Pathogens and Transactions of the Royal Society of Tropical Medicine and Public Health

\section{CONCLUSION}

Conclude that as countries in the Indian subcontinent progress towards the elimination goal of Leismaniasis in the affected regions, the concern is that elimination may be mistaken for eradication, and both donor fatigue and programme complacency may drift attention to the next unfinished agenda. The challenge now is to ensure that the disease does not re-emerge or is not reintroduced and that disease and vector surveillance is reinforced during the post-elimination phase. The strategy needs a paradigm shift from preventing disease to preventing infection and interrupting transmission. The development of innovative approaches to impair infection through early case detection and treatment, particularly in remote or previously non-endemic areas, as well as vector surveillance systems, new methods to measure transmission, mathematical transmission modelling to measure progress post elimination, xeno-diagnostic studies to measure reservoir potential, new non-invasive antigen-based diagnostic tools, better treatment of post kala-azar dermal leishmaniasis and surveillance for drug resistance are some of the urgent research priorities for the immediate future. Further research is needed on insecticide resistance monitoring, sandfly breeding and feeding habits, and the impact of IRS on transmission of Visceral Leishmaniasis between the host and vector. Continuing investment in translational research from the bench to the bedside to public health is imperative to block transmission and prevent a resurgence of Visceral Leishmaniasis in the future.

\section{SUMMARY}

- The global research output in the field of Leishmaniasis research had originated from as many as 158 countries, of which the top 10 most productive countries account for $95.57 \%$ global publication share during 2008-17, which increased from $92.26 \%$ to 98.62\% from 2008-12 to 2013-17. Among top 10 countries, Brazil 
accounted for the highest publication share (22.95\%), followed by USA (17.78\%), India (12.32\%), U.K., Iran and Spain (from 7.21\% to $8.20 \%$ ), France. Germany, Italy and Switzerland (from $4.13 \%$ to 5.95\%) during 2008-17. The global publication share in five years increased in Brazil, Iran, Spain, India and Italy, as against decrease in USA, U.K., Spain, Switzerland and Germany from 2008-12 to 2013-17. Seven of the top 10 countries scored relative citation index above the world average of 1.32: Switzerland (2.17), Italy (2.0), U.K. (1.93), France (1.86), USA (1.80), Spain (1.58) and Germany (1.43) during 2008-17. Seven countries have achieved share of high cited papers above the average (1.65) of top 10 countries: U.K. (3.43), USA (3.27), Switzerland (3.03), Italy (2.95), France (2.21), Germany (1.90) and Spain (1.73) during 2008-17.

- India had produced 1970 publications in Leishmaniasis research as indexed in Scopus database in 10 years during 2008-17. These publications increased from 145 to 211 from the year 2008 to year 2017, registering $17.68 \%$ annual growth. India's global publications share in in Leishmaniasis research was $12.32 \%$ during $2008-17$, which increased from $11.81 \%$ to $12.78 \%$ from $2008-12$ to $2013-17$. India's citation impact in Leishmaniasis research averaged to 17.28 citations per publication during 2008-17, which dropped from 27.07 to 8.96 from $2008-12$ to 2013-17. The share of international collaborative papers of India in its research output in Leishmaniasis was $26.85 \%$ during $2008-17$, which increased from $26.54 \%$ to $27.18 \%$ from $2008-12$ to $2013-17$. Medicine, among subjects, accounted for the highest publications share (55.43\%), followed by biochemistry, genetics and molecular biology (32.94\%), immunology and microbiology (31.68\%), pharmacology, toxicology and pharmaceutics $(20.81 \%)$, chemistry $(7.77 \%)$ and agricultural and biological sciences (7.56\%) during 2008-17.

- The top 15 most productive Indian organizations and authors together contributed $78.38 \%$ and $57.06 \%$ respectively as their share of Indian publication output and $95.86 \%$ and $52.23 \%$ respectively as their share of Indian citation output during 2008-17. The leading most productive Indian organizations contributing to Leishmaniasis research were Banaras Hindu University, Varanasi (301 papers), Indian Institute of Chemical Biology, Kolkata (258 papers), Central Drug Research Institute, Lucknow (212 papers) and Rajendra Memorial Institute of Medical Sciences, Patna (207 papers) during 2008-17. The leading Indian organizations with comparatively higher citation impact per paper were All India Institute of Medical Sciences, New Delhi (105.23), Postgraduate Institute of Medical Education and Research, Chandigarh (61.36) and Banaras Hindu University, Varanasi (22.25) during 2008-17.
- The leading most productive Indian authors contributing to Leishmaniasis research were S. Sundar (243 papers), P. Das (205 papers), K. Pandey (86 papers) and A. Dube (82 papers) during 2008-17. The leading Indian authors with comparatively higher citation impact per paper were J. Chakravarty (35.33), S. Sundar (23.37), N. Ali (20.0), S. Gupta (16.26), S. Roy (16.06), P. Salotra (15.94) during 2008-17.

- Of the 1603 journal publications (published in 749 journals) from India on Leishmaniasis research, the top 15 most productive journals accounted for $26.17 \%$ share of total Indian journal publication output during $2008-17$, which decreased from $26.43 \%$ to $25.95 \%$ from 2008-12 and 2013-17. The top most productive journal was PLOS Neglected Tropical Disease (84 papers), followed by PLOS One (69 papers), Experimental Parasitology (42 papers), American Journal of Tropical Medicine and Hygiene (41 papers), Antimicrobial Agents (35 papers), etc. during 2008-17.

- Only 20 papers out of 1970 papers registered citations from 102 to 5725 citations per paper during 2008-17, which together received 211897 citations, leading to an average of 594.85 citations per paper. The USA, U.K. and Switzerland accounted for the highest number of papers (6), followed by Belgium (4 papers), Canada, Germany and Nepal (3 papers each), Australia and Bangladesh (2 papers each), etc. These 20 highly cited papers were published in 16 journals, with 4 papers in The Lancet, followed by 2 papers in Clinical Infectious Diseases and 1 paper each in other 14 journals.

\section{REFERENCES}

1. Who. Regional Office for Africa. Leishmaniasis. 2017. http://www.afro.who.int/ health-topics/Leishmaniasis (Accessed on 10 June 2018)

2. WHO. Leishmaniasis. Key Facts. 14 March 2018. http://www.who.int/newsroom/fact-sheets/detail/leishmaniasis (Accessed on 10 June 2018)

3. Talniya NC. The status of Visceral leishmaniasis in India. Journal of Chemical and Pharmaceutical Research. 2016;8(8):195-201.

4. Ramos JM, González-Alcaide G, Bolaños-Pizarro M. Bibliometric analysis of leishmaniasis research in Medline (1945-2010). Ramos et al. Parasites and Vectors 2013,6:55.http://www.parasitesandvectors.com/content/6/1/55.https://doi. org/10.1186/ 1756-3305-6-55@

5. González-Alcaide G, Huamaní C, Jinseo P, Ramos JM. Evolution of coauthorship networks: Worldwide scientific production on leishmaniasis. Revista da Sociedade Brasileira de Medicina Tropical. 2013;46(6):719-27.

6. Soosaraeia M, Akbar K, Ali FM, Hezarjaribic HZ. A decade bibliometric analysis of global research on leishmaniasis in Web of Science database. Annals of Medicine and Surgery. 2018;26:30-7.

7. Perilla-Gonzalez Y, Gomez-Suta D, Delgado-Osorio N, Hurtado-Hurtado N, Baquero-Rodriguez JD, Lopez-Isaza AF, Lagos-Grisales GJ. Villegas, Soraya and Rodriguez-Morales, Alfonso J. Study of the Scientific Production on Leishmaniasis in Latin America. Recent Patents on Anti-Infective Drug Discovery. $2014 ; 9(3): 216-22$

Cite this article: Ahmed KKM, Gupta BM, Gupta R. Leishmaniasis Research in India: A scientometric Assessment of Publications During 2008-17. Int J Med Public Health. 2018; 8(3):96-103. 